\title{
Potential Use of Cuticular Hydrocarbons in Estimating the Age of Blowfly Pupae Chrysomya megacephala (Diptera: Calliphoridae)
}

\author{
RIZOH BOSORANG*1, ZAINI ASSIM ${ }^{2}$, SULAIMAN HANAPI $^{1} \&$ FATIMAH ABANG $^{1}$ \\ ${ }^{1}$ Department of Zoology, ${ }^{2}$ Department of Chemistry, Faculty of Resource Science and Technology, \\ Universiti Malaysia Sarawak, 94300 Kota Samarahan, Sarawak, Malaysia \\ *Corresponding author: rizohbosorang@gmail.com
}

\begin{abstract}
Gas chromatography coupled with mass spectrometry (GC-MS) was used to determine the weathering time in cuticular hydrocarbon of pupae Chrysomya megacephala in sheltered condition. The results have shown that cuticular hydrocarbons ( $\mathrm{CHC}$ ) of the pupae were a mixture of $n$-alkanes, methyl-branched alkanes, and dimethyl-branched alkanes, with carbon chain length ranging from $\mathrm{C}_{19}$ to $\mathrm{C}_{39}$. The study presents the significant correlation between the changes pattern in relative abundance of several $\mathrm{CHC}$ and development phase in pupae. Further analysis with multiple linear regression indicated that several CHC compounds showed strong correlation to blowfly pupae age, which were then utilized to create a prediction equation for the age estimation. Finally, the application of the age-dependent model had revealed that estimated age correlated significantly with chronological age of samples $C$. megacephala., $\mathrm{y}=0.97 \mathrm{x}+0.092, \mathrm{R}^{2}=0.9698$. The study concluded that, $\mathrm{CHC}$ have a potential to estimate age of immature $C$. megacephala, and possibly in other flies species, and might further be used to determine the PMI.
\end{abstract}

Keywords: Chrysomya megacephala, blowfly pupae, cuticular hydrocarbons, gas chromatography-mass spectrometry

\section{INTRODUCTION}

Calliphorids are often used to estimate the postmortem interval (PMI) on human remains as they are recognized as the first wave of the faunal succession (Amendt et al., 2004). However, forensic investigators always encounter serious difficulties when estimating the time of death of human remains that are in an advanced state of decomposition. Usually, age of fly larvae estimated by rearing them into adult stage and PMI is calculated based on the total development time (Gennard, 2007). However, the age of the fly inside the puparium is more difficult to be estimated. For example, Chrysomya megacephala undergo pupation for about 75-90 hours and it could lead to error in the estimation of up to 2-3 days if PMI estimation involving pupae developmental stage (Salleh et al., 2009). Therefore, the use of cuticular hydrocarbon profile analysis may resolved the issue highlighted by estimating the age of the insect specimens directly.

The variation in proportions of several cuticular hydrocarbon compounds at different stages of development have been reported (Blomquist et al., 1999; Brown et al., 2000; Nelson \& Charlet, 2003; Hugo et al., 2006). Their differences can also be detected throughout their developmental cycle (Juarez \& Fernandez, 2007). Qualitatively, the cuticular hydrocarbon patterns are species-specific, and at the same time changes in the composition of cuticular hydrocarbons during development have been observed. Buckner et al. (1999) reported that the composition of cuticular waxes from different development stages is concurrent with the development process of an individual. It therefore showed that the changes in profile of cuticular hydrocarbons were due to the ecdysis and development stages.

The quantitative variations on the profile of cuticular hydrocarbons at different stages of development provides more argument about the availability of cuticular hydrocarbons as an alternative biological marker for species recognition. On the other hand, inconsistencies in the distribution of cuticular hydrocarbons in insects give the impression that there is a correlation between hydrocarbon production and development of insect cuticle. If the pattern changes occurred in cuticular hydrocarbon composition is consistent at different development stages, the changes in cuticular hydrocarbon composition would be correlated to the age of the insect. 
Therefore, the present study was conducted to examine the changes occurred in the composition of cuticular hydrocarbons on the pupae of a forensically important blowfly $C$. megacephala and correlates to the pupae age. If the changes reflecting the pupae development process and can be incorporated into a model, $\mathrm{CHC}$ could be a very useful tool for estimating the age of pupae and hence could facilitate PMI estimation involving immature specimen.

\section{MATERIALS AND METHODS}

\section{Specimen Collections and Identification}

A total of 50 pupae of blow fly C. megacephala from Kota Samarahan, Sarawak were collected from rearing containers, comprises of 10 individuals per day for five consecutive days. The specimens were collected on a daily basis and referred to as chronological age of the pupae samples. The specimens collected were frozen at $-20^{\circ} \mathrm{C}$ before hydrocarbons extraction (Page et al., 1990), and they were identified by comparing them with voucher specimens at the Unimas Zoology Museum and also by using identification keys from Kurahashi and Leh (1997).

\section{Cuticular Hydrocarbon Extraction}

Frozen specimen were allowed to warm up to ambient temperature prior to extraction. Cuticular hydrocarbons were extracted by immersing specimen in $2 \mathrm{~mL}$ chloroform for 1 minute (Chapman et al., 1995). The extract was then allowed to evaporate at room temperature until dry and then redissolved with $2 \mathrm{~mL}$ of $n$ hexane. The hydrocarbon extract was separated from the unwanted lipids by passage through a glass column chromatography packed with 3 $\mathrm{cm}$ of activated Biosil A (silica gel, 100-200 mesh) following that of Page et al. (1990) and eluted three times with $2 \mathrm{~mL}$ of $n$-hexane. After the removal of solvent by evaporated to dryness under a stream of nitrogen, the extract was then redissolved in $50 \mu \mathrm{L} n$-hexane for analysis by gas chromatography-flame ionization detector (GC-FID) and gas chromatography-mass spectrometry (GC-MS).

\section{Gas Chromatographic Analysis}

GC-MS analysis was performed using a Shimadzu QP5000 PLUS (GC/MS) in splitless injection mode fitted with a fused silica capillary column (30 $\mathrm{m} \times 0.25 \mathrm{~mm}$ i.d., BPX5, $25 \mu \mathrm{m}$ film), using the scan mode with the mass range was scanned from 45 to 650 a.m.u. The initial temperature was set at $80^{\circ} \mathrm{C}$ and hold for 5 minutes, then programmed at $5^{\circ} \mathrm{C} / \mathrm{min}$ to final temperature $300^{\circ} \mathrm{C}$, with a final holding time of 10 minutes and the detector temperature set at $320^{\circ} \mathrm{C}$. Purified nitrogen gas at a flow rate of $1.5 \mathrm{~mL} / \mathrm{min}$ and helium was used as a carrier gas. The mass spectra of the methyl-branched alkanes were interpreted according to the criteria proposed by Nelson et al. (1972). Retention times were compared with $n$-alkanes standard. The identified compounds were further confirmed by comparing their mass spectra with those mass fragmentation patterns in National Institute of Standards and Technology (NIST) standard library.

\section{Statistical Analysis}

Quantitative approach for statistical analysis was performed with SPSS 19.0 version for ANOVA and stepwise discriminant function analysis (DFA) and multiple linear regression analysis (LRA). While, Solo Matlab 7.9.0 version for principal component analysis (PCA) and hierarchical cluster analysis (HCA). Stepwise DFA was carried out to select the hydrocarbon components that could effectively discriminate samples into their respective groups. While, a graphical representation of differentiating age of larvae C. megacephala was illustrated with PCA and HCA. LRA presented the best model in which then utilized to create prediction equation for the pupae age estimation. The chromatographic data (relative percentage of composition based on the integrated peak areas) were transformed into corresponding mathematical values prior to multivariate analysis.

\section{RESULTS AND DISCUSSION}

Figure 1 shows the GC chromatograms for comparison of the hydrocarbon profiles from the extracts of $C$. megacephala for five different pupae ages with the hydrocarbon profile ranging from $\mathrm{C}_{17}$ to $\mathrm{C}_{40}$. The pattern of peaks on chromatogram marked with ' $\mathrm{U}$ ' or ' $\mathrm{M}$ ' shaped representing mean (\%) of $\mathrm{CHC}$ across five different pupae ages, as shown in Figure 1, signify the composition and distribution of $\mathrm{CHC}$ profile of this species. 
The three shaded bars in Figure 1 show areas of contrast within the GC traces detected among samples of pupae across five consecutive days. Bar 1 to bar 3 highlights one peak or two peaks that show contrast in relative abundance of the compound, some peaks are not shaded although they are significantly different in ANOVA. For example, peak 37 and peak 40 represents two different compounds that contrast in relative abundance, for at least in one of the five pupae groups of age.

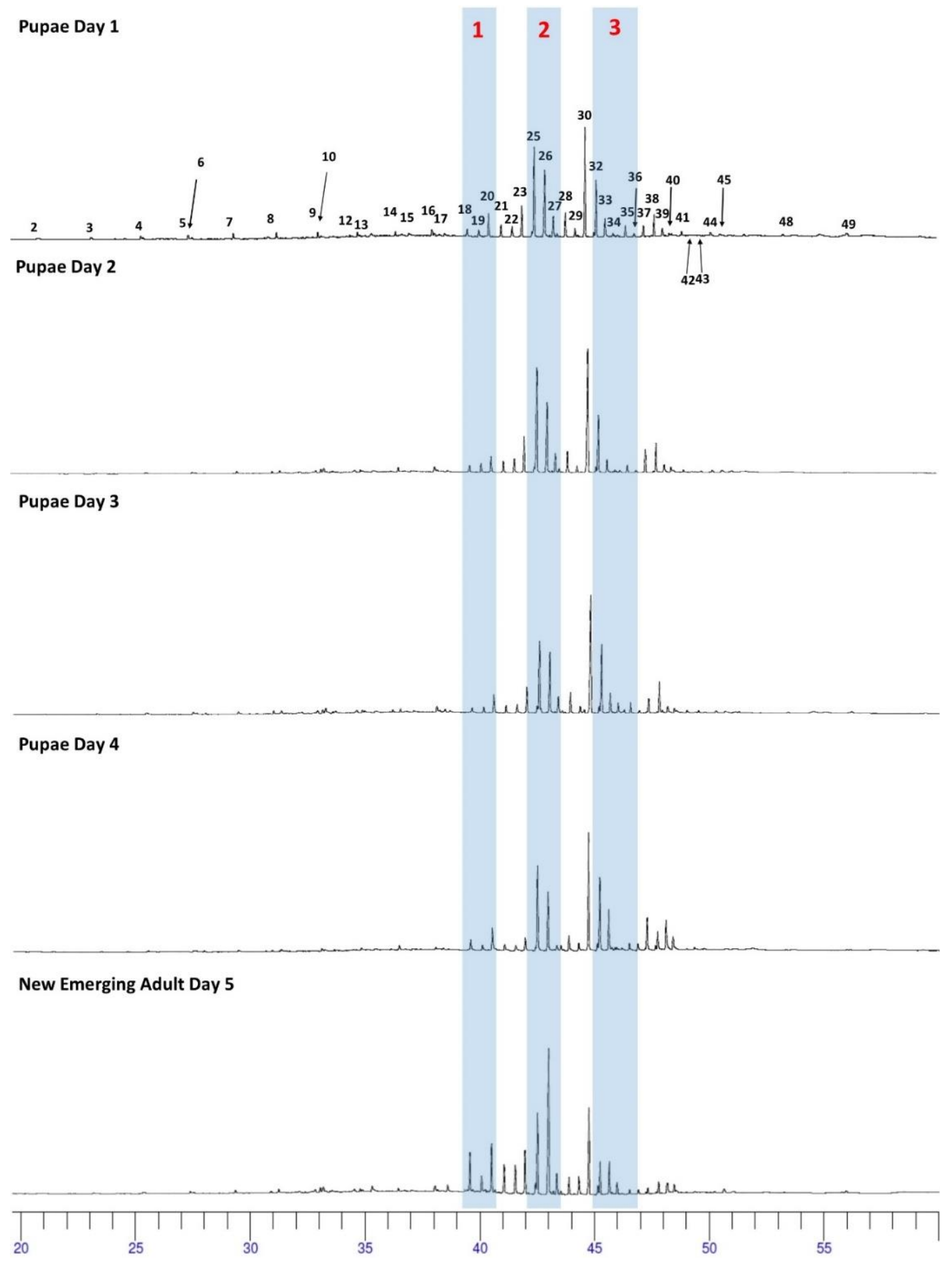

Figure 1. Chromatogram of CHCs pupae of C. megacephala collected for five consecutive days including newly emerged adult fly. Bar 1 to 3 highlights one peak or two peaks that show contrast in relative abundance of the compound. 
The CHCs of $C$. megacephala for five different pupae ages were found to consist of a mixture of $n$-alkanes, alkenes, methyl-branched alkanes, which is similar to that of $\mathrm{CHCs}$ compound between localities. Furthermore the data obtained from gas chromatography analysis revealed that 45 hydrocarbon compounds were commonly detected for ten replicates samples of five different groups of pupae age, but mean relative proportions of several compounds varied significantly at $\mathrm{p}$ values $<0.01$. Table 1 also indicates that $n-\mathrm{C}_{30}$ (peak 25), 15- $\mathrm{MeC}_{30}$ (peak 26), 9,12-diMeC 31 (peak 30), and $n-\mathrm{C}_{32}$ (peak 32) were found to be dominant compounds, and could be used as marker in the profile of pupae C. megacephala. The CHC patterns for flies from the five different pupae ages were similar. This observation gives insight that $\mathrm{CHC}$ of pupae $C$. megacephala at five different ages was consistent, thus making samples of pupae difficult to differentiate into its respective ages.

No dominant compound exceeding $20 \%$ of the total $\mathrm{CHC}$ relative abundance were detected in $\mathrm{CHC}$ profiles. Five different groups represent pupae age showed some considerable differences when looking at their chemical profile so it is expected that they would be distinguishable when statistical analysis is applied. Analysis of variance signified that there was a significant difference of proportions of $\mathrm{CHC}$ compounds between five different pupae ages, whereby 23 out of 45 $\mathrm{CHC}$ compounds show significance at p-value $<0.001$. The highest variance of $\mathrm{CHC}$ compounds between the five different pupae ages was $13,17-\mathrm{diMeC}_{34}$, followed by 13 $\mathrm{MeC}_{27}$ and $13-\mathrm{MeC}_{28}$ with $\mathrm{F}$ values were 249.01, 221.74 and 152.41, respectively. ANOVA result give an idea that branched alkanes would become major compounds in determining pupae ages.

Stepwise discriminant analysis was conducted to evaluate the relative proportion (in \%) of all 50 types of $\mathrm{CHC}$ detected in all samples examined. A total of $100.0 \%$ variance in the data set was explained by the first four discriminant functions of both DFA. Whereby, $85.8 \%, 10.5 \%$ and $3.4 \%$ of variance explained by the first three functions. Stepwise DFA had indicated eight $\mathrm{CHC}$ compounds that reasonably cluster the adult samples into their respective ages, comprises of an $n$-alkane, an alkene and six branched alkanes. Overall, the first DFA had successfully classified all samples into five correct groups in $100 \%$ of cases, with cross-validation resulting in an error of $0.0 \%$.

PCA based on nine CHC compounds obtained from stepwise DFA was carried out using three principal component analysis describing $87.35 \%$ of the variation within the dataset. The three principal components comprising $40.71 \%, 28.31 \%$ and $10.34 \%$, respectively. PC1 vs PC2 were used to plot the relevant score in the PCA. Figure 2 (right) indicate PCA showing three clusters display in a different spatial positioning on the scatter plot, and that were corresponded to three major pupae ages. PCA also does not enable to classify samples into five distinct group although the segregation of scatter plot had improved. Thus, result suggest that pupae samples collected from five consecutive days were able to classify into three major group of age based on nine CHC compounds obtained from stepwise DFA.

PCA were further computed using similar data, with the removal of pupae of day 5 in the dataset. PCA consist of seven CHC compounds obtained from stepwise DFA was carried out using five principal component analysis describing $97.68 \%$ the total variance. The first three principal components comprising $46.70 \%, 15.94 \%$ and $13.11 \%$, respectively. PC1 vs PC2 were used to plot both the relevant score and loading. Again, similar to previous PCA, two major clusters were constructed instead of four clusters, showing three clusters of pupae were overlapping to each other, except pupae of day 4 as shown in Figure 2 (right). Again, the distribution of the score plot revealed that there is overlapping clusters between adult day 1 , day 2 , and day 3 with large variation within group age. The PCA result propose that $\mathrm{CHC}$ compounds are able to discriminate pupae into two major groups, earlier pupae age and later pupae age. 
Table 1. Hydrocarbon compounds identified in the cuticle of pupae C. megacephala. The data listed the common hydrocarbons detected in all samples examined during GC-MS analysis.

\begin{tabular}{|c|c|c|c|c|c|c|c|c|c|c|c|c|c|}
\hline \multirow{2}{*}{ No. Peak } & \multirow{2}{*}{$\begin{array}{c}\text { Retention } \\
\text { Time }\end{array}$} & \multirow{2}{*}{$\begin{array}{l}\text { Kovats } \\
\text { Indices }\end{array}$} & \multirow{2}{*}{$\begin{array}{c}\text { Shorthand } \\
\text { Nomenclature }\end{array}$} & \multicolumn{2}{|c|}{ Day $1, n=10$} & \multicolumn{2}{|c|}{ Day 2, n=10 } & \multicolumn{2}{|c|}{ Day 3, $n=10$} & \multicolumn{2}{|c|}{ Day 4, $n=10$} & \multicolumn{2}{|c|}{ Day $5, n=10$} \\
\hline & & & & Mean & Std. E & Mean & Std. E & Mean & Std. E & Mean & Std. E & Mean & Std. E \\
\hline 2 & 20.618 & 1800 & $n$-C $\mathrm{C}_{18}$ & 0.04 & 0.02 & 0.04 & 0.01 & 0.04 & 0.02 & 0.05 & 0.01 & 0.05 & 0.01 \\
\hline 3 & 22.585 & 1900 & $n-\mathrm{C}_{19}$ & 0.09 & 0.03 & 0.07 & 0.02 & 0.08 & 0.01 & 0.07 & 0.01 & 0.06 & 0.02 \\
\hline 4 & 24.556 & 2000 & $n-\mathrm{C}_{20}$ & 0.17 & 0.06 & 0.15 & 0.03 & 0.15 & 0.02 & 0.16 & 0.02 & 0.13 & 0.03 \\
\hline ? & 26.316 & 2096 & $1-C_{21}$ ene & 0.05 & 0.01 & 0.04 & 0.01 & 0.04 & 0.00 & 0.03 & 0.01 & 0.05 & 0.01 \\
\hline 5 & 26.438 & 2100 & $n-\mathrm{C}_{21}$ & 0.21 & 0.08 & 0.24 & 0.05 & 0.19 & 0.03 & 0.22 & 0.05 & 0.16 & 0.03 \\
\hline 6 & 28.498 & 2200 & $n-\mathrm{C}_{22}$ & 0.26 & 0.05 & 0.22 & 0.08 & 0.28 & 0.07 & 0.26 & 0.06 & 0.29 & 0.07 \\
\hline 7 & 30.465 & 2300 & $n-\mathrm{C}_{23}$ & 0.56 & 0.08 & 0.59 & 0.09 & 0.54 & 0.06 & 0.58 & 0.06 & 0.54 & 0.21 \\
\hline ? & 32.215 & 2395 & $5-\mathrm{C}_{24} \mathrm{ene}$ & 0.78 & 0.11 & 0.76 & 0.19 & 0.71 & 0.11 & 0.73 & 0.08 & 0.63 & 0.14 \\
\hline 8 & 32.392 & 2400 & $n-\mathrm{C}_{24}$ & 0.49 & 0.18 & 0.53 & 0.15 & 0.51 & 0.03 & 0.57 & 0.08 & 0.60 & 0.15 \\
\hline 11 & 34.282 & 2500 & $n-C_{25}$ & 0.64 & 0.14 & 0.68 & 0.14 & 0.71 & 0.12 & 0.69 & 0.09 & 0.56 & 0.16 \\
\hline 12 & 34.729 & 2560 & $11 / 13-\mathrm{MeC}_{25}$ & 0.29 & 0.08 & 0.26 & 0.12 & 0.24 & 0.02 & 0.28 & 0.09 & 0.38 & 0.18 \\
\hline 14 & 35.865 & 2600 & $n-\mathrm{C}_{26}$ & 0.64 & 0.10 & 0.65 & 0.13 & 0.66 & 0.10 & 0.67 & 0.08 & 0.76 & 0.12 \\
\hline 15 & 36.400 & 2632 & $13-\mathrm{MeC}_{26}$ & 0.08 & 0.02 & 0.08 & 0.02 & 0.08 & 0.03 & 0.06 & 0.02 & 0.07 & 0.02 \\
\hline 16 & 37.532 & 2700 & $n-\mathrm{C}_{27}$ & 1.01 & 0.14 & 1.05 & 0.24 & 1.19 & 0.08 & 1.25 & 0.08 & 1.31 & 0.42 \\
\hline 17 & 38.528 & 2748 & $11 / 13-\mathrm{MeC}_{27}$ & 0.08 & 0.02 & 0.10 & 0.01 & 0.09 & 0.01 & 0.09 & 0.01 & 1.22 & 0.24 \\
\hline 18 & 39.100 & 2800 & $n-\mathrm{C}_{28}$ & 0.87 & 0.10 & 0.84 & 0.07 & 0.87 & 0.14 & 0.99 & 0.12 & 4.35 & 0.91 \\
\hline 19 & 39.593 & 2834 & $14-\mathrm{MeC}_{28}$ & 0.93 & 0.06 & 0.92 & 0.15 & 0.45 & 0.19 & 0.56 & 0.09 & 1.82 & 0.16 \\
\hline 20 & 40.102 & 2870 & 7,11-diMeC 28 & 4.35 & 0.37 & 4.30 & 1.13 & 4.10 & 0.41 & 4.31 & 0.57 & 5.49 & 0.88 \\
\hline 21 & 40.639 & 2900 & $n-\mathrm{C}_{29}$ & 1.62 & 0.16 & 1.52 & 0.29 & 1.43 & 0.14 & 1.48 & 0.16 & 1.64 & 0.43 \\
\hline 22 & 41.094 & 2945 & $13-\mathrm{MeC}_{29}$ & 1.49 & 0.15 & 1.57 & 0.13 & 1.48 & 0.22 & 1.57 & 0.29 & 3.23 & 0.62 \\
\hline 23 & 41.549 & 2954 & $13,17-\mathrm{diMeC}_{29}$ & 5.60 & 0.24 & 5.10 & 0.22 & 4.94 & 0.21 & 4.33 & 0.30 & 3.75 & 0.23 \\
\hline 24 & 41.985 & 2988 & $11,15,19$-triMeC 29 & 0.00 & 0.00 & 0.00 & 0.00 & 0.00 & 0.00 & 0.00 & 0.00 & 0.03 & 0.01 \\
\hline 25 & 42.107 & 3000 & $n-\mathrm{C}_{30}$ & 15.47 & 0.42 & 14.66 & 0.29 & 14.28 & 0.41 & 13.85 & 0.43 & 12.73 & 0.59 \\
\hline 26 & 42.552 & 3031 & $15-\mathrm{MeC}_{30}$ & 12.19 & 0.73 & 12.22 & 1.06 & 11.68 & 1.03 & 11.51 & 0.88 & 18.27 & 1.51 \\
\hline 27 & 42.903 & 3056 & $13,17-\mathrm{diMeC}_{30}$ & 3.89 & 0.40 & 3.65 & 0.34 & 3.24 & 0.49 & 2.38 & 0.29 & 2.44 & 0.36 \\
\hline 28 & 43.528 & 3100 & $n-\mathrm{C}_{31}$ & 5.12 & 0.38 & 4.48 & 0.30 & 4.13 & 0.37 & 3.57 & 0.35 & 2.46 & 0.40 \\
\hline 29 & 43.927 & 3129 & $15-\mathrm{MeC}_{31}$ & 1.86 & 0.28 & 1.92 & 0.29 & 1.88 & 0.16 & 1.85 & 0.24 & 2.06 & 0.38 \\
\hline 30 & 44.388 & 3163 & 9,12 -diMeC 31 & 18.25 & 0.73 & 18.36 & 0.96 & 19.32 & 1.56 & 18.63 & 1.05 & 14.92 & 0.69 \\
\hline 31 & 44.771 & 3191 & $7,11,15$-triMeC ${ }_{31}$ & 0.00 & 0.00 & 0.01 & 0.00 & 0.00 & 0.00 & 0.00 & 0.00 & 0.03 & 0.01 \\
\hline 32 & 44.901 & 3200 & $n-\mathrm{C}_{32}$ & 9.44 & 0.80 & 9.32 & 0.76 & 9.49 & 1.00 & 8.93 & 0.97 & 7.94 & 1.52 \\
\hline 33 & 45.281 & 3229 & $15-\mathrm{MeC}_{32}$ & 3.33 & 0.74 & 3.74 & 0.84 & 4.25 & 0.34 & 5.01 & 0.63 & 3.90 & 0.50 \\
\hline 34 & 45.590 & 3252 & $13,17-\mathrm{diMeC}_{32}$ & 0.35 & 0.10 & 0.58 & 0.13 & 0.87 & 0.09 & 1.13 & 0.18 & 1.73 & 0.30 \\
\hline 35 & 46.225 & 3300 & $n-\mathrm{C}_{33}$ & 1.38 & 0.24 & 1.56 & 0.38 & 1.60 & 0.19 & 1.46 & 0.24 & 1.26 & 0.24 \\
\hline 36 & 46.510 & 3322 & $15-\mathrm{MeC}_{33}$ & 0.41 & 0.09 & 0.40 & 0.07 & 0.39 & 0.04 & 0.38 & 0.05 & 0.39 & 0.15 \\
\hline 37 & 47.019 & 3362 & $11,21-\mathrm{diMeC}_{33}$ & 2.08 & 0.28 & 2.55 & 0.42 & 1.65 & 0.20 & 3.67 & 0.28 & 0.86 & 0.18 \\
\hline 38 & 47.512 & 3400 & $n-\mathrm{C}_{34}$ & 4.41 & 0.61 & 4.24 & 0.69 & 4.93 & 0.53 & 5.16 & 0.58 & 1.71 & 0.21 \\
\hline 39 & 47.865 & 3431 & 12 -diMeC 34 & 1.31 & 0.15 & 1.47 & 0.17 & 1.62 & 0.21 & 3.54 & 0.31 & 1.76 & 0.40 \\
\hline 40 & 48.110 & 3453 & $13,17-\mathrm{diMeC}_{34}$ & 0.12 & 0.03 & 0.21 & 0.03 & 0.45 & 0.12 & 0.87 & 0.10 & 1.37 & 0.16 \\
\hline 41 & 48.651 & 3500 & $n-\mathrm{C}_{35}$ & 0.15 & 0.03 & 0.15 & 0.03 & 0.15 & 0.02 & 0.14 & 0.01 & 0.15 & 0.02 \\
\hline 42 & 49.023 & 3532 & $11-\mathrm{MeC}_{35}$ & 0.00 & 0.00 & 0.00 & 0.00 & 0.00 & 0.00 & 0.00 & 0.00 & 0.00 & 0.00 \\
\hline 44 & 49.798 & 3600 & $n-\mathrm{C}_{36}$ & 0.09 & 0.02 & 0.12 & 0.02 & 0.13 & 0.01 & 0.18 & 0.02 & 0.23 & 0.04 \\
\hline 45 & 50.182 & 3631 & $13-\mathrm{MeC}_{36}$ & 0.09 & 0.02 & 0.06 & 0.02 & 0.08 & 0.01 & 0.06 & 0.01 & 0.04 & 0.01 \\
\hline 46 & 50.654 & 3669 & $12,22-\mathrm{diMeC}_{36}$ & 0.00 & 0.00 & 0.00 & 0.00 & 0.00 & 0.00 & 0.00 & 0.00 & 0.00 & 0.00 \\
\hline 47 & 51.039 & 3700 & $n-\mathrm{C}_{37}$ & 0.08 & 0.03 & 0.06 & 0.02 & 0.05 & 0.02 & 0.04 & 0.01 & 0.02 & 0.01 \\
\hline 48 & 52.131 & 3800 & $n-\mathrm{C}_{38}$ & 0.10 & 0.04 & 0.08 & 0.05 & 0.07 & 0.02 & 0.06 & 0.01 & 0.03 & 0.02 \\
\hline $\begin{array}{l}40 \\
49\end{array}$ & 53.326 & 3900 & $\begin{array}{l}n-C_{38} \\
n-C_{3}\end{array}$ & $\begin{array}{l}0.104 \\
0.04\end{array}$ & $\begin{array}{l}0.04 \\
0.02\end{array}$ & 0.06 & $\begin{array}{l}0.03 \\
0.02\end{array}$ & 0.06 & 0.02 & 0.05 & $\begin{array}{l}0.01 \\
0.01\end{array}$ & 0.02 & 0.01 \\
\hline
\end{tabular}

Notes: - Values are the averages and standard deviations for 10 samples of pupae $C$. megacephala for each day age, obtained from GC-FID.

- Compounds were determined from GC-MS analysis. The peaks that represent less than $0.01 \%$ were not included.

- No. of peak correspond to the CGC profile in adult C. megacephala (not included in this analysis), whereby '?' refers to compound that only detected in pupae development stage. 

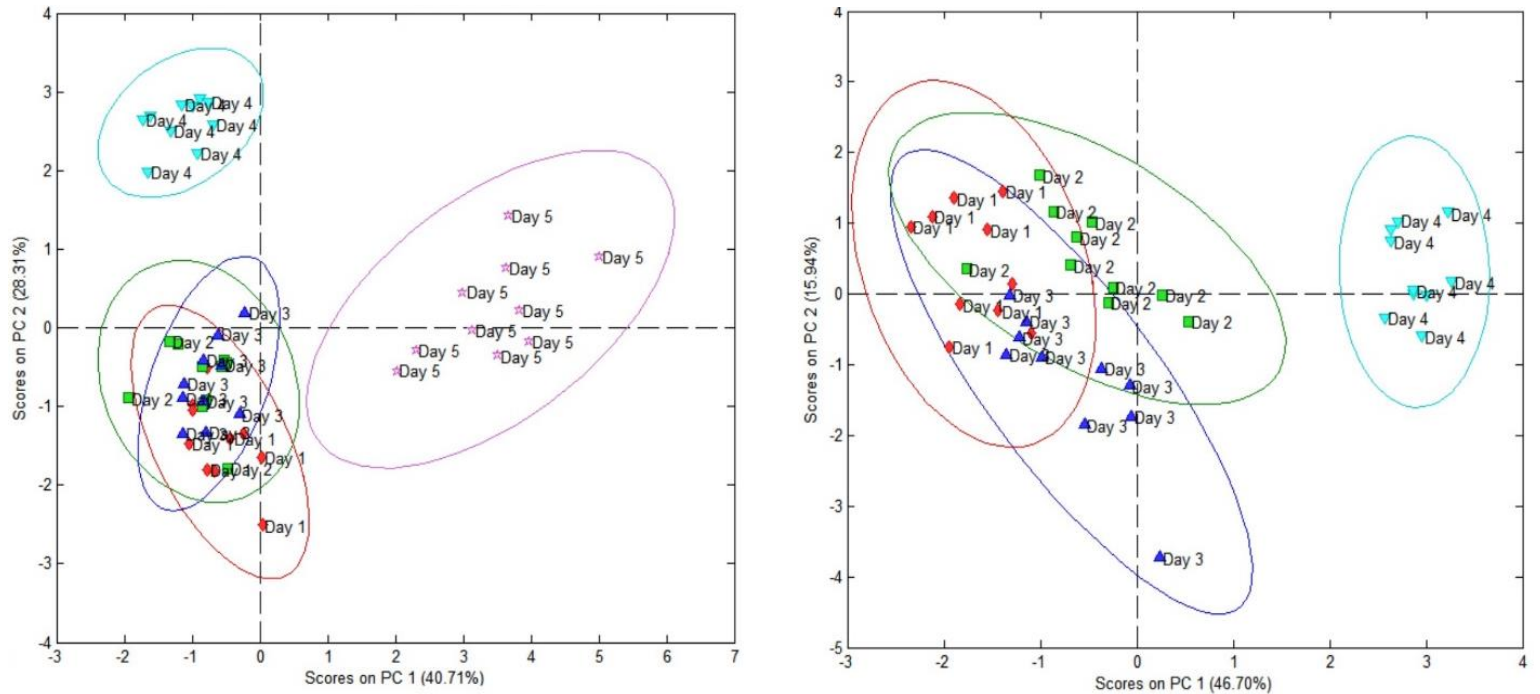

Figure 2. PCA displaying the score plot representing 50 samples of pupae $C$. megacephala based on CHC obtained from stepwise DFA, data from day 5 included (left) and data from day 5 removed (right).

A Pearson correlation coefficient was computed to assess the relationship between the relative abundance (proportion in \%) of $\mathrm{CHC}$ compounds and the ages of pupae samples from day 1 to 5 . Result shown in Table 2 indicate nine CHC compounds were have correlation to pupae ages, with correlation Pearson (r) value range 0.700 and above ( $\mathrm{p}$-value $<0.001$ ), where the highest $\mathrm{r}$ value with $0.945,0.929$, and 0.925 , were belong to $13,17-$ diMeC $_{34}, 13,17$ $\mathrm{diMeC}_{29}$ and 13,17-diMeC 32 , respectively. A total of five out those nine $\mathrm{CHC}$ compounds showed negative $r$ value, which suggest relative abundance of these compounds from pupae of day 1 gradually decreased toward pupae of day 5. Overall, there was a strong correlation between relative abundant of several $\mathrm{CHCs}$ compounds and pupae ages. Hence, the finding propose that several $\mathrm{CHC}$ compounds are capable of reflecting the ages of pupae fly.

Linear regression for curve estimation was computed to find which $\mathrm{CHC}$ compounds have strong linear regression $\left(\mathrm{R}^{2} \leq 0.800\right)$ toward age of pupae $C$. megacephala. The results indicated that four compounds represent at least $R^{2} \leq 0.800$. The highest $R^{2}$ belong to $13,17-$ diMeC $_{34}$ with $\mathrm{R}^{2}$ value of 0.892 $(\mathrm{F}=397.63$, $\mathrm{p}<0.001)$, followed by 13,17 $\operatorname{diMeC}_{29}, 13,17-\mathrm{diMeC}_{32}$ and $n-\mathrm{C}_{31}$ with $\mathrm{R}^{2}$ value of $0.863(\mathrm{~F}=302.10, \mathrm{p}<0.001), 0.856$ $(\mathrm{F}=286.08,=1.387)$, respectively. 13,17 $\operatorname{diMeC}_{34}$ and 13,17-diMeC 32 show that their relative abundance was gradually increased from pupae day 1 to pupae day 5 as seen in Figure 3.

Table 2. Correlation between CHC compounds and of pupal ages. Correlation with value of $r \geq 0.70$ included in the table.

\begin{tabular}{lllc}
\hline \multicolumn{1}{c}{ Range } & \multicolumn{1}{c}{ Name of Compounds } & \multicolumn{1}{c}{$\begin{array}{c}\text { Shorthand } \\
\text { Nomenclature }\end{array}$} & Correlation, $\mathbf{r}$ \\
\hline $0.90 \leq \mathrm{r}$ & 13,17-Dimethyltetratriacontane & $13,17-\mathrm{diMeC}_{34}$ & 0.945 \\
& 13,17-Dimethylnonacosane & $13,17-\mathrm{diMeC}_{29}$ & -0.929 \\
& 13,17-Dimethyldotriacontane & $13,17-\mathrm{diMeC}_{32}$ & 0.925 \\
& $n$-hentriacontane & $n$ - $\mathrm{C}_{31}$ & -0.914 \\
$0.80 \leq \mathrm{r}<0.90$ & $n$-Triacontane & $n$ - $\mathrm{C}_{30}$ & -0.892 \\
& $n$-Hexatriacontane & $n$ - $\mathrm{C}_{36}$ & 0.888 \\
& 13,17-Dimethyltriacontane & $13,17-\mathrm{diMeC}_{30}$ & -0.824 \\
$0.70 \leq \mathrm{r}<0.80$ & $n$-Heptatriacontane & $n$-C & -0.733 \\
& $n$-Octacosane & $n$ - $\mathrm{C}_{28}$ & 0.700 \\
\hline
\end{tabular}



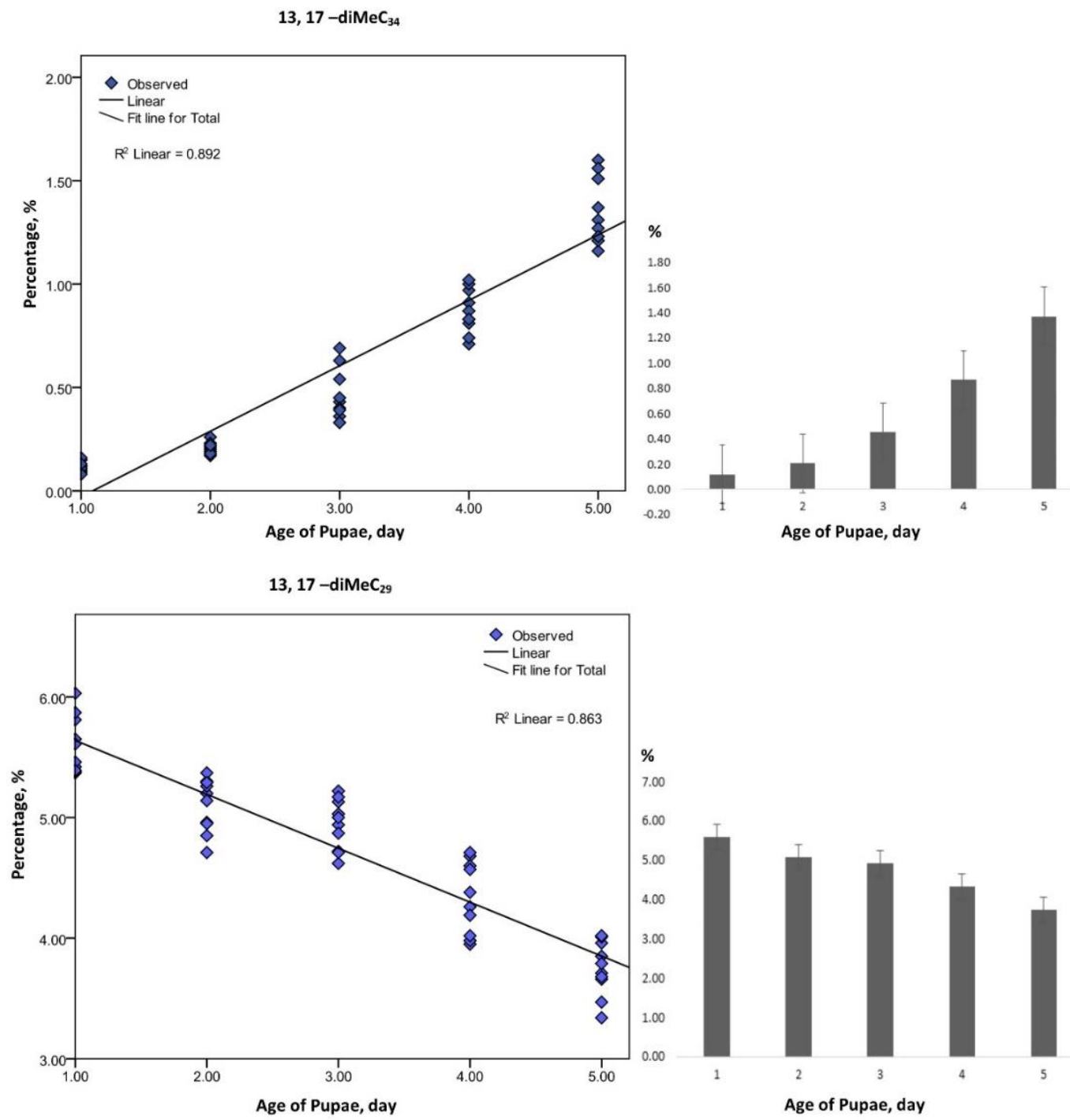

Figure 3. Age-dependent change in relative abundance of 13,17-diMeC 34 and 13,17-diMeC 29 . A total of 50 samples collected from five consecutive days of pupae stage represented in scatter plot (left), and mean relative abundance of mean samples (right).

Multiple linear regression analyses was conducted to determine which independent variables (CHC compounds) could be used to develop a model for predicting pupae age of $C$. megacephala. The regression analysis using those peaks that satisfied the following criteria: (1) the area percentage equal to or over $1 \%$ in at least an age cohort of the pupae; (2) highly significant correlation between peak ratio and chronological age. Regression analysis indicated all five model of predictors that significantly predict pupae age. The five predictors were included $13,17-\mathrm{diMeC}_{34}, \mathrm{n}-\mathrm{C}_{30}$, 7,14- $\mathrm{MeC}_{28}, 13-\mathrm{MeC}_{29}$, 13,17-diMeC 29 , with $\mathrm{R}^{2}=0.988, \mathrm{R}^{2}$ adj $=0.987, \mathrm{~F}(4,45)=962.717, \mathrm{p}$ $<0.001$.
This model accounted for $98.8 \%$ of variance in pupae age estimation. A summary of the regression model was presented in Table 3 . In addition, bivariate and partial correlation coefficients between each predictor and the dependent variable were presented in Table 4. The coefficient for the model, was utilized to create a prediction equation for the pupae age estimation. The following equation was generated using the B weight in the Table 4: y (a) -0.373 (b) -0.970 (c) +0.478 (d) $\mathrm{p}<0.001)$ and $0.836(\mathrm{~F}=244.82, \mathrm{p}<0.001)-$ 0.5287 (e) +10.301 , where y stands for the pupae age (day). Application of the above agedependent model revealed that estimated age correlated significantly with chronological age 
Table 3. Model summary represent predictors that significantly predict pupal age.

\begin{tabular}{cccccccccc}
\hline Model & Step & $\boldsymbol{R}$ & $\boldsymbol{R}^{\mathbf{2}}$ & $\boldsymbol{R}_{\text {adj }}^{2}$ & $\boldsymbol{\Delta R}^{\mathbf{2}}$ & $\boldsymbol{F}_{\boldsymbol{c h g}}$ & $\boldsymbol{p}$ & $\boldsymbol{d} \boldsymbol{f}_{\boldsymbol{I}}$ & $\boldsymbol{d f}_{\boldsymbol{2}}$ \\
\hline 1 & $13,17-\mathrm{diMeC}_{34}$ & .945 & .892 & .890 & .892 & 397.63 & $<.001$ & 1 & 48 \\
2 & $n-\mathrm{C}_{30}$ & .960 & .922 & .919 & .030 & 17.83 & $<.001$ & 1 & 47 \\
3 & $14-\mathrm{MeC}_{28}$ & .974 & .948 & .945 & .026 & 23.49 & $<.001$ & 1 & 46 \\
4 & $13-\mathrm{MeC}_{29}$ & .979 & .958 & .954 & .010 & 10.31 & .002 & 1 & 45 \\
5 & $13,17-\mathrm{diMeC}_{29}$ & .985 & .970 & .966 & .012 & 17.30 & $<.001$ & 1 & 44 \\
\hline
\end{tabular}

Table 4. Coefficient for final model used for pupae age prediction.

\begin{tabular}{ccccccc}
\hline Code & Variable & $\boldsymbol{B}$ & $\boldsymbol{\beta}$ & $\boldsymbol{t}$ & Bivariate $\boldsymbol{r}$ & Partial $\boldsymbol{r}$ \\
\hline & (Constant) & 10.301 & & $8.977^{*}$ & & \\
$\boldsymbol{a}$ & $13,17-\mathrm{diMeC}_{34}$ & 1.387 & 0.465 & $6.080^{*}$ & 0.945 & 0.676 \\
$\boldsymbol{b}$ & $n-\mathrm{C}_{30}$ & -0.373 & -0.263 & $-4.994^{*}$ & -0.892 & -0.602 \\
$\boldsymbol{c}$ & $14-\mathrm{MeC}_{28}$ & -0.97 & -0.342 & $-6.978^{*}$ & 0.402 & -0.725 \\
$\boldsymbol{d}$ & $13-\mathrm{MeC}_{29}$ & 0.478 & 0.254 & $4.240^{*}$ & 0.656 & 0.539 \\
$\boldsymbol{e}$ & $13,17-\mathrm{diMeC}_{29}$ & -0.596 & -0.287 & $-4.16^{*}$ & -0.929 & -0.531 \\
\hline
\end{tabular}

Note: *Indicates significance at $\mathrm{p}<0.001$.

of pupae C. megacephala with a linear function of $y=0.97 x+0.092(R 2=0.9698, p$ $<0.01)$ as shown in Figure 4.

Several studies have suggested that cuticular hydrocarbons can be used to identify or establish the age of forensically important for blowfly immature stages, since changes occurred over time in their CHC profile (Zhu et al., 2007; Roux et al., 2008; Moore et al., 2014). The PCA couple with stepwise DFA facilitates the quantification of variability in the overall hydrocarbon profile of the cuticle hydrocarbons both within each day and from day to day across the whole time-span of the experiment. Although the loading plot does not relate directly to any particular compound, the output of the calculation does allow the key compounds that are involved in changes to be identified. Several hydrocarbon components were screened and used to establish a multiple regression equation for successful determination of age of the pupae.

It is extremely difficult to estimate the age of pupae using morphological changes. Hence, Zehner et al. (2006) had highlighted that genetic analysis with PCR technique applied difficult to determine the age of blowfly pupae. Thus, propose that the fragment patterns may rather correspond with the origin of the genetic lineage than with the development stage. In contrast, preliminary study by Ames et al. (2006) has indicated that the differing expression of genes in the developmental lifecycle of blowfly $C$. vicina can be used to age immature insects. Later on, DNA techniques being developed to look into agegrading this life stage using gene expression with a good degree of success (Zehner et al., 2009).

Given the developments in DNA analysis and the results it gives on the potential for estimating the age of immature insects, the hydrocarbon analysis may be better applied when compared to DNA analysis. In theory, the composition of the $\mathrm{CHCs}$ is predictable in fresh pupae and changes regularly over time. This makes the pupae $\mathrm{CHC}$ method promising for determining the weathering time of the pupae and then for the late PMI. However, in this study, ageing results for this life stage using $\mathrm{CHC}$ analysis proved to be less successful, where only three major ages were determined instead of five different group age. Therefore, this procedure needs to be repeated with more samples replicate to validate the age group established, and involving different species of blowflies.

\section{CONCLUSION}

This present study had highlighted the potential used of $\mathrm{CHC}$ analysis as a complement to the current techniques to determine ages of forensically important blowfly $C$. megacephala at pupae stages. The 


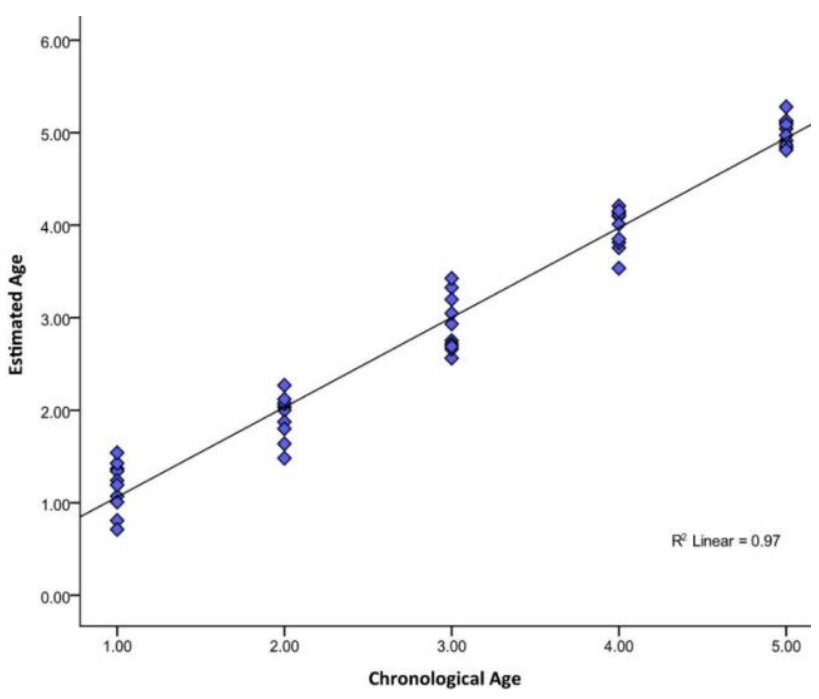

Figure 4. Relationship between estimated age based on the CHCs and chronological age of pupae $C$. megacephala, which can be well fitted by a linear function: $\mathrm{y}=0.97 \mathrm{x}+0.092, \mathrm{R}^{2}=0.9698$.

study also presented the significant correlation of the pattern changes in relative abundance of several CHC across five consecutive days on development phase of pupae C. megacephala. Further analysis with linear regression and curve estimation indicated that several $\mathrm{CHC}$ compounds showed strong correlation to blowfly ages, which were then utilized to create a prediction equation for the pupae age estimation. Finally, the application of the agedependent model (prediction of equation) had revealed that the estimated pupae age correlated significantly $\left(\mathrm{R}^{2}=0.9698\right)$ with chronological age of samples pupae $C$. megacephala in a linear fashion.

\section{ACKNOWLEDGEMENT}

The authors wish to acknowledge DPI grant Universiti Malaysia Sarawak, 01(DPI12)870/2013(04), for funding this project.

\section{REFERENCES}

Amendt, J., Krettek, R., \& Zehner, R. (2004). Forensic entomology. Naturwissenschaften, 91(2): 51-65.

Ames, C., Turner, B., \& Daniel, B. (2006). Estimating the post-mortem interval (II): The use of differential temporal gene expression to determine the age of blowfly pupae. International Congress Series, 1288: 861-863.
Blomquist, G.J., Mpuru, S., Schqal, C., Roux, M., Kuenzli, M., Dusticier, G., Clement, J., \& Bagneres, A. (1999). Effect of age and sex on the production of internal and external hydrocarbons and pheromones in the housefly, Musca domestica. Insects Biochemistry and Molecular Biology, 31: 139-155.

Buckner, J.S., Hagen, M.M., \& Nelson, D.R. (1999). The composition of the cuticular lipids from nymphs and exuviae of silverleaf whitefly, Bemisia argentifolii. Comparative Biochemistry and Physiology Part B, 124: 201-207.

Brown, W.V., Rose, H.A., Lacey, M.J., \& Wright, K. (2000). The cuticular hydrocarbons of the giant soil-burrowing cockroach Macropanesthia rhinoceros Saussure (Blattodea: Blaberidae: Geoscapheinae): analysis with respect to age, sex and location. Comparative Biochemistry and Physiology Part B, 127: 261-277.

Chapman, R.F., Espelies, K.E., \& Swords, G.A. (1995). Use of cuticular lipids in grasshopper taxonomy: a study of variation in Schistocerca shoshone (Thomas). Biochemical Systematics and Ecology, 23: 383-398.

Gennard, D.E. (2007). Forensic entomology: An introduction. Chichester: John Wiley \& Sons.

Hugo, L.E., Kay, B.H., Eaglesham, G.L., Holling, N., \& Ryan, P.A. (2006). Investigation of cuticular hydrocarbons for determining the age and survivorship of Australasian mosquitoes. American Journal of Tropical Medicine and Hygiene, 74(3): 462-474.

Juarez, M.P. \& Fernandez, G.C. (2007). Cuticular hydrocarbons of triatomines. Comparative Biochemistry and Physiology Part A, 147: 711730. 
Kurahashi, H. \& Leh, M.U. (2007). The flies from Sarawak, East Malaysia (Diptera: Muscidae, Calliphoridae, Sarcophagidae and Tachinidae). Medical Entomology and Zoology, 58: 261-273.

Moore, H.E., Adam, C.D., \& Drijfhout, F.P. (2014). Identifying $1^{\text {st }}$ instar larvae for three forensically important blowfly species using "fingerprint' cuticular hydrocarbon analysis. Forensic Science International, 240: 48-53.

Nelson, D.R. \& Charlet, L.D. (2003). Cuticular hydrocarbons of sunflower beetles, Zygogramma exclamationis. Comparative Biochemistry and Physiology Part B, 102(3): 451-470.

Nelson, D.R., Sukkestad, D.R., \& Zaylskie, R.G. (1972). Mass spectra of methyl-branched hydrocarbons from eggs of the tobacco hornworm, Journal of Lipid Research, 13: 413421.

Page, M., Nelson, L.J., Haverty, M.I., \& Blomquist, G.J. (1990). Cuticular hydrocarbons chemotaxonomic character for bark beetles: Dendroctonus ponderosae, D. jeffreyi, D. brevicomis, and D. frontalis (Coleoptera: Scolytidae). Annual Meeting of the Entomological and Society of America, 83: 892901.
Roux O., Gers, C., \& Legal, L. (2008). Ontogenetic study of three Calliphoridae of forensic important through cuticular hydrocarbon analysis. Medical and Veterinary Entomology, 22: 309-317.

Salleh, M.A.F., Talib, A., Marwi, M.A., Hamid, N.A.A., Abdullah, S.R., Zuha, R.M., \& Omar, B. (2009). Effects of temperature on larval development of Chrysomya megacephala (Fabricius) and Chrysomya rufifacies (Macquart) (Diptera: Calliphoridae): Application in forensic science. Journal of Health Science Malaysia, 7(2): 89-96.

Zehner, R., Mosch, S., \& Amendt, J. (2006). Estimating the post mortem interval by determining the age of fly pupae: Are there any molecular tools? International Congress Series, 619-621.

Zehner, R., Amendt, J., \& Boehme, P. (2009). Gene expression analysis as a tool for age estimation of blowfly pupae. Forensic Science International: Genetics Supplement Series, 2: 292-293.

Zhu, G.H., Xiao, H.X., Xiao, J.Y., Zhang, Y., \& Wang, J.F. (2007). Puparial case hydrocarbons of Chrysomya megacephala as an indicator of the postmortem interval. Forensic Science International, 169(1): 1-5. 